\title{
Papilomavírus Humano (HPV) entre Jovens: um sinal de alerta
}

\section{Human Papillomavirus (HPV) among Youth: a warning sign}

\author{
Larissa Aparecida Costa \\ Mestre em Ciências. \\ Endereço: Rua Tomazinho Resende, 260, Bairro Daniel Fonseca, \\ CEP 38400-326, Uberlândia, MG, Brasil. \\ E-mail: larissapsico®hotmail.com \\ Paulete Goldenberg \\ Professora Doutora do Programa de Pós-Graduação em Saúde \\ Coletiva da UNIFESP. \\ Endereço: Rua São Giusto, 99, Bairro Jardim Lusitânia, CEP 04030- \\ 030, São Paulo, SP, Brasil. \\ E-mail: pauletegoldenæhotmail.com
}

\section{Resumo}

O Papilomavírus Humano - HPV - assume especial destaque na Saúde Pública diante do reconhecimento de sua associação com a ocorrência do câncer uterino, entre outros. Levando em conta a necessidade de implementação de programas de esclarecimentos sobre a prevenção dos agravos relacionados à infecção pelo HPV, coloca-se o propósito da realização do presente diagnóstico sobre conhecimentos e práticas sexuais entre jovens. Direcionando, estrategicamente, para o segmento de universitários, o estudo foi realizado no Campus da Baixada Santista da UNIFESP, estruturado em torno da formação multiprofissional em saúde. O levantamento foi feito a partir da aplicação de questionário em sala de aula, junto aos alunos do primeiro e terceiro ano. Com uma concentração de iniciação sexual na faixa de 15 a 17 anos de idade, os alunos referiram uso de preservativos masculinos associado à preocupação com a contracepção, secundada pela prevenção de Doenças Sexualmente Transmissíveis - DSTs. O conhecimento sobre o HPV foi restrito na população investigada. Embora crescente do primeiro para o terceiro ano, sua apreciação é relativizada quanto ao conhecimento da transmissão, consequências e prevenção. A investigação apontou a necessidade de disponibilizar informações relativas ao HPV em atenção às especificidades da doença.

Palavras-chave: Saúde pública; Comportamento sexual; Papilomavirus humano; Prevenção de doenças transmissíveis. 


\section{Abstract}

Human Papillomavirus (HPV) assumes an important focus in public health care mainly because recognition of its association with cancer, especially cervix cancer. The purpose of this study was to characterize the level of knowledge about HPV infection and preventive practices among youths, with intention to support health care protocols. Descriptive data collection enrolled a self-completion questionnaire, addressed to first and third year health care college students of Campus Baixada Santista of Federal University of Sao Paulo - UNIFESP. With age of sexual initiation concentrated between 15 and 17 years old, respondents referred use of preventive methods during the first sexual relation firstly associated to concern about pregnancy and followed by Sexually Transmitted Disease - STD prevention. Restrict knowledge about HPV was referred by the students. Although acquaintance of HPV increased from the first year to the third year, incomprehension was shown regarding its transmission, consequences or prevention. This survey revealed the need for available information regarding characteristics of HPV disease.

Keywords: Public Health; Sexual Behaviour; Human Papillomavirus; Prevention of Transmitted Diseases.

\section{Introdução}

O papilomavírus humano (HPV) constitui um problema reatualizado de saúde pública na década de 8 o diante do reconhecimento de sua associação com o câncer de colo uterino (Nagakawa e col., 2010) - o segundo tumor mais frequente e a quarta causa de morte por câncer na população feminina do Brasil (Frigato e Hoga, 2003). Existem mais de 100 tipos de HPV, sendo que cerca de 15 (tipos 16, 18, 31, 33, 45,58 e outros) são considerados de alto risco para malignidade (Bricks, 2007).

De etiologia viral, a transmissão do HPV dá-se nas formas sexual, por contato e pela via materno fetal (gravidez, intra e periparto) (Queiroz e col., 2007). Ao lado do espectro diferenciado das vias de transmissão, acrescenta-se a invisibilidade de grande parte das manifestações da infecção - o que dificulta a percepção de sua presença.

O HPV acomete homens e mulheres afetando tanto a região genital como a extragenital. A infecção pode manifestar-se nas formas clínica, subclínica e latente (Carvalho e col., 2007), sendo predominantes as formas subclínica e assintomática entre os homens. Assim, eles são considerados propagadores do vírus - o que não exclui a possibilidade de desenvolverem a doença (Costa, 2008). A forma mais prevalente da infecção, entre as mulheres, é subclínica e clínica, e mais de 90,0\% das infecções regridem espontaneamente (Einstein e col., 2009). Fatores como estado imunológico, tabagismo, herança genética, hábitos sexuais e uso prolongado do contraceptivo oral contribuem para a persistência da infecção e a progressão para lesões intraepiteliais (Castellsagué, 2008).

A prevenção do desenvolvimento do HPV comporta o tratamento e remoção das verrugas via/e cauterização; e, a prevenção do contágio desse vírus admite utilização das vacinas (bivalente e quadrivalente); uso de métodos de barreiras nas relações sexuais; cuidados higiênicos (Carvalho e col., 2007; Sankaranarayanan, 2009). Acrescenta-se, a propósito da prevenção dos agravos associados ao HPV, a questão da persistência e do progresso da infecção, ao lado da possibilidade de reincidência, que evidencia a importância do diagnóstico precoce.

Considerando a complexidade da ocorrência do 
HPV, destaca-se a preocupação em se valorizar os sentidos da prevenção na população juvenil, subjacente ao desencadeamento da vivência sexual.

O comportamento sexual se alterou ao longo dos anos, passando de um padrão tradicional - que privilegiava a sexualidade associada à reprodução - para a liberação sexual. Desvinculada a atividade sexual da reprodução, destaca-se, em primeira instância, a questão da prevenção da gravidez (Guerra e Gouveia, 2007). No decorrer desse movimento, registra-se o aumento das Doenças Sexualmente Transmissíveis - DSTs, o que amplificaria o escopo da preocupação com a prevenção circunscrita em torno da contracepção. A propósito, com o advento da Síndrome da Imunodeficiência Adquirida - AIDS, dissemina-se a proposta do uso de preservativos masculinos associado à prática do "sexo seguro". Heilborn e colaboradores (2006) registraram o aumento de sua utilização entre jovens - a despeito das resistências, sempre presentes.

Neste contexto, o reconhecimento da importância do HPV e dos agravos associados emerge como um novo desafio no âmbito da saúde pública, levando em conta as especificidades das formas de transmissão e de manifestação ao longo da vida. Lembrando que o preservativo não elimina totalmente o risco de contrair o vírus (Arcoverde e Wall, 2005), a recusa ao seu uso constitui sério entrave para os programas de prevenção. Reforçando as tradicionais hierarquias de gênero, esta disposição de recusa compromete a corresponsabilidade necessária entre parceiros, quando se trata da prevenção do HPV.

Este quadro suscita indagações sobre a importância atribuída à problemática da infecção pelo HPV. Quais informações subjacentes às práticas preventivas estão presentes no universo daqueles que estão na fase inicial da vida sexual? Informações básicas sobre etiologia, transmissão e desenvolvimento da doença colocam-se como conteúdos cognitivos indispensáveis para a construção das atitudes, referenciadas à vulnerabilidade. Nesta perspectiva, para além do risco (sentido estrito), segundo Ayres e colaboradores (1999), impõe-se a consideração da subjetividade (no plano individual) que na confluência com as condições sociais, econômicas e culturais (no plano coletivo) estruturam a dinâmica da construção dos enfrentamentos das questões de saúde. Sob esta ordem de consideração, coloca-se o propósito da realização, em caráter exploratório, do levantamento sobre conhecimento do HPV e práticas preventivas entre jovens, direcionado, estrategicamente, para um segmento de universitários, por se tratar de um grupo de maior nível de escolarização, supostamente com acesso diferenciado a informações.

\section{Metodologia}

Foi realizado um estudo descritivo, de corte transversal, que visou acessar a faixa etária de adultos jovens. Por uma questão de conveniência, a investigação concentrou-se no Campus da Baixada Santista da UNIFESP, que congrega cursos voltados para a formação de profissionais da área da saúde. Esse Campus foi inaugurado em 2005, com graduações em Nutrição, Psicologia, Terapia Ocupacional, Fisioterapia e Educação Física. O curso de Serviço Social foi inaugurado somente em 2009 - neste caso, participaram da coleta de dados apenas alunos da primeira série.

O levantamento foi realizado junto a universitários de ambos os sexos, levando em conta a abordagem na perspectiva de gênero. Considerando que nas quartas séries os alunos não têm presença continuada devido aos estágios, o estudo restringiu-se aos alunos dos primeiros e dos terceiros anos, com o propósito de obter indicativos de conhecimentos diferenciados sobre as DSTs / HPV possivelmente associados ao incremento das práticas sexuais.

Os dados foram obtidos a partir de questionário, constituído de perguntas abertas e fechadas. Este instrumento foi aplicado, pela própria pesquisadora, em sala de aula, sendo garantido o sigilo das informações. Uma vez realizada a proposta, os alunos tiveram a liberdade de ficar em sala para responder ou não - a saída da sala foi considerada como uma recusa não informada, ao lado dos alunos faltosos no dia da coleta. Nestas condições, participaram da pesquisa 146 alunos do primeiro ano: 26 do curso de Nutrição, 33 do curso de Psicologia, 18 do curso de Serviço Social, 26 do curso de Terapia Ocupacional, 27 do curso de Fisioterapia e 16 do curso de Educação Física. Com exceção destes últimos, cuja proporção em relação aos alunos da série alcançou 
$43 \%$, todos os alunos dos demais cursos tiveram uma representação superior a 50\% em relação às respectivas séries.

A coleta, realizada em 3 dias consecutivos entre alunos do primeiro ano, ocorreu no primeiro semestre de 2009, enquanto que entre os alunos do terceiro ano, a aplicação do questionário foi realizada também em 3 dias consecutivos, no segundo semestre de 2009.

Com relação aos participantes do terceiro ano, aderiram à pesquisa 33 alunos do curso de Nutrição, 28 do curso de Psicologia, 24 do curso de Terapia Ocupacional, 36 do curso de Fisioterapia e 16 do curso de Educação Física, resultando num total de 137 alunos. Proporção menor de adesão (39\%) também foi registrada entre alunos do curso de Educação Física; nos demais cursos a proporção de participação foi superior a 70\% das respectivas séries, tendo atingindo 79\% no curso de Terapia Ocupacional.

A caracterização do perfil sociodemográfico dos estudantes envolveu informações sobre idade, sexo, cor, naturalidade, local de residência, escolaridade dos pais e condições de manutenção econômica do aluno.

A idade, computada em anos completos, foi categorizada em faixas etárias, sendo excluídos os alunos com idade inferior a 18 anos diante da exigência de autorização por parte dos responsáveis. Ao lado da identificação dos alunos segundo sexo, o levantamento registrou: a cor autorreferida; a naturalidade, levando em conta a localização do município referenciada à Baixada Santista, capital ou interior do Estado de São Paulo, entre outros Estados; o lugar de residência e com quem conviviam (familiares, amigos, outros). Como indicador de extração socioeconômica, foi considerada a escolaridade dos pais referenciada ao último nível (completo) de ensino. Além disso, foi considerado se o aluno trabalhava, tendo em vista suas condições de autonomia econômica.

A segunda parte do questionário contemplou o comportamento sexual do aluno com foco na primeira e última relação sexual. A propósito, foi indagada aos estudantes a idade que tinham na ocasião do primeiro intercurso; se a relação sexual havia sido um evento inesperado ou programado; e se o relacionamento teve continuidade. No caso da última relação, foram levantados informes sobre quando ela se deu; se a relação ocorreu com parceiro fixo, se envolvia relações heterossexuais ou homossexuais (masculinas/femininas) e com qual frequência ocorriam.

Em relação ao uso de recursos preventivos (com referência à primeira e última relação) foi especificado o tipo de "método" utilizado (preservativo masculino, preservativo feminino, pílula anticoncepcional, DIU - dispositivo intrauterino, coito interrompido, tabelinha, diafragma e outros). O levantamento envolveu o questionamento do motivo da escolha do recurso utilizado, assim como do não uso, sempre referenciada a preocupação com a contracepção e/ ou prevenção de doença.

Com a intenção de verificar as fontes de informações sobre as DSTs, foi indagado com quem os alunos costumavam falar a respeito: amigos, familiares, escola. Sobre isso, o estudo registrou informações relativas à procura de serviços de saúde (relacionados à atividade sexual): qual tipo de serviço eles buscavam (Sistema Único de Saúde - SUS, médico particular, convênio) e os motivos da procura (prevenção de gravidez; informações sobre DSTs; tratamento).

Na terceira parte do questionário, foram formuladas questões sobre conhecimentos relativos às DSTs. Ao lado do reconhecimento das doenças nesse âmbito, foi considerado o grau de importância atribuído a elas, numa escala de o a 4. A propósito do HPV, foram levantadas informações a respeito da transmissão, suscetibilidade à infecção entre homens e mulheres, complicações associadas ao seu desenvolvimento e formas de prevenção - incluindo, entre os recursos disponíveis, a utilização da vacina.

Finalmente, foi perguntado ao aluno se ele desejaria obter informações sobre o HPV/DSTs, sendo solicitadas sugestões a respeito.

Os dados foram processados em EXCELL, sendo expressos em números e porcentagens. Como se tratava de uma amostra de conveniência, foi privilegiada, para efeito do presente trabalho, a abordagem qualitativa. Diante desta opção, as respostas dos estudantes às questões abertas foram transcritas. Procedendo à identificação das unidades de sentido, devidamente categorizadas, elas foram reportadas ao contexto das relações sociais que inscrevem a problematização em torno do conhecimento e prá- 
ticas preventivas em relação ao HPV.

O projeto de pesquisa foi aprovado pelo Comitê de Ética da UNIFESP. A coleta de dados junto aos cursos foi devidamente autorizada pela instituição. Depois da apresentação da pesquisa em sala de aula, acrescida das explicações sobre a garantia do sigilo das informações, a liberação do questionário foi condicionada à assinatura do termo de consentimento livre e esclarecido.

\section{Resultados e Discussão}

Os alunos do Campus Baixada Santista são jovens, com idades entre 18 e 23 anos. Na população investigada, predominaram alunos do sexo feminino (primeiro ano: 74,0\% e terceiro ano: 86,9\%), de cor branca $(79,5 \%$ e 75,9\% na primeira e terceira séries, respectivamente). Provenientes principalmente da capital e do interior do Estado de São Paulo - poucos são naturais da Baixada Santista $(8,9 \%$ no primeiro e 10,2\% no terceiro ano). 0 afluxo de alunos provenientes de outras cidades, certamente, é uma decorrência do atrativo de ingresso numa escola pública, em meio ao estrangulamento do acesso ao ensino universitário, associado a diferenciais sociais de oportunidades.

Com níveis semelhantes de escolaridade, enquanto indicação de extração social, foi significativa a presença de pais com nível superior tanto entre alunos do primeiro ano (50,0\%) como do terceiro ano $(58,4 \%)$. Entre as mães, estas porcentagens caem para 35,0\% em detrimento da proporção mais elevada do nível médio. Estes resultados são condizentes com o aumento da escolarização no País, em meio à valorização do ensino universitário como condição para inserção no mercado de trabalho, ao mesmo tempo em que sinalizam para a seletividade do processo de acesso ao terceiro nível de ensino.

Exigindo a presença em período integral, grande proporção dos alunos reside em Santos (primeiro ano: $65,1 \%$ e terceiro ano: $77,4 \%$ ) especialmente com amigos. Sendo basicamente sustentados pelos pais (primeira série: 94,5\% e terceira série: 97,1\%), a maioria dos estudantes não trabalha.

Mais da metade dos alunos participantes da pesquisa já havia iniciado a vida sexual no momento da realização da investigação, sendo esta proporção maior no terceiro $(81,0 \%)$ do que no primeiro ano $(65,8 \%)$. Como indicativo da persistência de diferenciais de gênero no contexto da liberação sexual, a proporção de iniciados foi superior a 94,0\% entre os alunos do sexo masculino, tanto no primeiro como no terceiro ano; na população feminina, estes valores foram de 55,5\% na primeira série e de 79,o\% na terceira série.

O estudo constatou, por sua vez, que a maioria dos alunos, tanto do primeiro $(62,5 \%)$ como do terceiro ano (49,5\%), iniciou a vida sexual com idades entre 15-17 anos; poucos tinham menos que 14 anos de idade $(8,3 \%$ e $3,6 \%$, respectivamente). A mediana da idade da primeira relação sexual entre os alunos foi de 16 anos e, entre alunas, de 17 anos. Estes valores são ligeiramente inferiores aos observados por Pirotta (2002, apud Borges e Schor, 2005, p. 500) que estudou, em 2002, uma amostra representativa de estudantes de graduação de uma universidade estadual paulista. Nesta amostra a autora encontrou uma mediana de idade da primeira relação sexual de 17 anos no grupo masculino e 18 anos no grupo feminino. Sem pretender estabelecer comparações, os resultados do presente estudo podem levantar a possibilidade - a ser investigada - de que a iniciação das atividades sexuais esteja ocorrendo mais precocemente.

Cerca de 50,0\% dos alunos do primeiro ano responderam que a primeira relação sexual foi inesperada, particularmente entre alunos do sexo masculino. Mais alunas do que alunos - tanto do primeiro (9o,o\%) quanto do terceiro ano $(77,6 \%)$ responderam que a relação teve continuidade após a iniciação sexual - evocando a persistência de diferenciais de comportamento sexual entre homens e mulheres.

No tocante à primeira relação sexual, 96 estudantes do primeiro ano e 111 do terceiro já tinham vivenciado essa experiência. Dentre eles, 83 (86,5\%) do primeiro ano e $97(87,4 \%)$ do terceiro ano alegaram ter usado algum tipo de contraceptivo nessa ocasião - tabela 1.

A utilização da camisinha masculina, como recurso exclusivo, foi mencionada por $61(63,5 \%)$ dos alunos do primeiro ano e por 58 (52,3\%) do terceiro ano; combinada com outros "métodos" (pílula e/ou tabelinha e/ou coito interrompido) a proporção foi 
Tabela I - Recursos preventivos utilizados na primeira relação sexual, segundo sexo (n, \%). Alunos do 우 e $3^{\circ}$ ano - UNIFESP/Campus Baixada Santista, 2009

\begin{tabular}{|c|c|c|c|c|c|c|c|c|c|c|c|c|}
\hline \multirow{3}{*}{ USO/ RECURSOS DE PROTEÇÃO } & \multicolumn{6}{|c|}{ PRIMEIRO ANO } & \multicolumn{6}{|c|}{ TERCEIRO ANO } \\
\hline & \multicolumn{2}{|c|}{ M } & \multicolumn{2}{|c|}{$\mathrm{F}$} & \multicolumn{2}{|c|}{ Total } & \multicolumn{2}{|c|}{ M } & \multicolumn{2}{|c|}{$\mathrm{F}$} & \multicolumn{2}{|c|}{ Total } \\
\hline & $n$ & $\%$ & $n$ & $\%$ & $\mathrm{n}$ & $\%$ & $n$ & $\%$ & $\mathrm{n}$ & $\%$ & $\mathrm{n}$ & $\%$ \\
\hline \multicolumn{13}{|l|}{ SIM } \\
\hline Só Cam. masculina & 23 & 63,9 & 38 & 63,4 & 61 & 63,5 & 10 & 58,8 & 48 & 51,1 & 58 & 52,3 \\
\hline \multicolumn{13}{|l|}{ Camisinha masculina+ } \\
\hline Pílula & 3 & 8,3 & 12 & 20,0 & 15 & 15,6 & 1 & 5,9 & 30 & 31,9 & 31 & 27,9 \\
\hline coito interromp. & - & - & 3 & 5,0 & 3 & 3,1 & - & - & - & - & - & - \\
\hline Tabelinha & - & - & 2 & 3,3 & 2 & 2,1 & 2 & 11,8 & - & - & 2 & 1,8 \\
\hline píl + coito interr. & - & - & 2 & 3,3 & 2 & 2,1 & - & - & - & - & - & - \\
\hline coito + tabel. + pil & - & - & - & - & - & - & - & - & 1 & 1,1 & 1 & 0,9 \\
\hline Só Pílula & - & - & - & - & - & - & - & - & 5 & 5,3 & 5 & 4,5 \\
\hline Sub-Total & 26 & 72,2 & 57 & 95,0 & 83 & 86,4 & 13 & 76,5 & 84 & 89,4 & 97 & 87,4 \\
\hline \multicolumn{13}{|l|}{ NÃO } \\
\hline Sub-Total & 10 & 27,8 & 3 & 5,0 & 13 & 13,6 & 4 & 23,5 & 10 & 10,6 & 14 & 12,6 \\
\hline Total Geral* & 36 & 100,0 & 60 & 100,0 & 96 & 100,0 & 17 & 100,0 & 94 & 100,0 & III & 100,0 \\
\hline
\end{tabular}

*Total geral de alunos iniciados sexualmente

de $22,9 \%$ entre alunos do primeiro ano e $30,6 \%$ no terceiro ano - totalizando mais de 8o,o\% de usuários em ambas as séries.

O uso da pílula, por sua vez, aparece de forma significativa $(5,3 \%)$, particularmente entre as referências das alunas do terceiro ano. Em que pese o viés de informações relativas ao passado, chamou a atenção o uso combinado da pílula - que revela a valorização não só da contracepção como da proteção referente à transmissão de DSTs.

A literatura nacional e internacional vem indicando aumento do uso de preservativos entre jovens em geral, particularmente no contexto da iniciação sexual. Considerada a principal estratégia de combate às DSTs, esse aumento remonta à época de emergência da epidemia da AIDS, e se torna mais intenso na década de 1990 (Vieira e col., 2004). Paiva e colaboradores (2008) evidenciaram maior uso do preservativo na primeira relação sexual entre os jovens brasileiros de 16 a 19 anos, que passou de $47,8 \%$ para $65,6 \%$ entre 1998 e 2005 . Em nosso estudo, as proporções do uso da camisinha masculina foram superiores a estes valores, reafirmando, em princípio, a tendência crescente do uso de preservativos no segmento de universitários. Mesmo considerando a possibilidade de essa informação não retratar "a verdade" - na medida em que o relato pode, inclusive, remeter a um padrão socialmente recomendável - é interessante notar que seu uso é referido por contingente significante de alunos, indicativo do valor dado à prevenção contra as DSTs, desde a iniciação sexual, ao lado da preocupação com a contracepção.

A propósito, inquiridos sobre os motivos para o uso de proteção na primeira relação sexual, os argumentos (tanto para os alunos do primeiro ano quanto do terceiro ano) gravitaram em torno da prevenção de gravidez, das DSTs ou de ambas: “... prevenção de gravidez indesejada”; “... o método previne contra DSTs"; "... proteção e prevenção contra as doenças e gravidez”. A despeito dos avanços no reconhecimento da adoção de práticas preventivas, a segmentação dos argumentos entre contracepção e proteção diante das doenças sexualmente transmissíveis ainda persiste, constituindo uma questão que não pode ser negligenciada.

O levantamento registrou, por outro lado, um segmento de alunos resistentes ao uso de qualquer recurso de proteção na primeira relação sexual, particularmente no segmento masculino - tabela 1. Mesmo se tratando de um agrupamento (privilegiado) de universitários, no conjunto, não fizeram uso 
de qualquer proteção 13,6\% dos alunos do primeiro e $12,6 \%$ dos alunos do terceiro ano. No segmento masculino, entretanto, estes valores atingiram $27,8 \%$ dos alunos (do sexo masculino) da primeira série e 23,5\% dos alunos da terceira série.

Certamente o não uso de proteção foi maior nos eventos inesperados, e isto pesou dentre os argumentos aventados para o comportamento adotado. Dentre as justificativas apontadas, inscrevem-se manifestações tais como: “... no impulso não pensei em usar, nem em possíveis consequências”; “... por falta de preparo, de planejamento"; "... não estava disponivel e não tinha como comprar" "... não quis usar, me senti confiante". Tais justificativas, na ambivalência de suas formulações, demonstram resistências e falta de informações em relação ao uso de contraceptivos, que não condizem com a prática do sexo seguro. Destacada a questão da falta de previsibilidade e acesso imediato ao contraceptivo, estas afirmações inscrevem-se no âmbito das racionalizações que sinalizam para a falta de esclarecimentos consequentes a ser perseguida no plano da prevenção do HPV/DST junto aos jovens.
Dentre os estudantes que já haviam iniciado a vida sexual, 63 alunos (65,6\%) da primeira série e 76 alunos $(68,5 \%)$ da terceira série eram sexualmente ativos na época da investigação. Quanto à característica da última relação sexual, prevaleceram relações heterossexuais, tendo sido mencionadas, em proporções residuais, relações homossexuais (3,9\%) e bissexuais (3,9\%) entre alunos do terceiro ano.

Entre os alunos sexualmente ativos, predominaram referência a relações com a presença de parceiros fixos. Não foram observadas diferenças por sexo entre alunos do primeiro ano; já no terceiro ano, as alunas $(78,0 \%)$ tinham mais relações com parceiros fixos do que os alunos (59,1\%), reverberando traços das diferenciações de gênero associadas ao comportamento sexual centrados na valorização da questão da reprodução, particularmente entre as mulheres, conforme colocações de Guerra e Gouveia (2007).

Dentre os participantes sexualmente ativos, quantidade significativa - $62(98,4 \%)$ alunos da primeira e $63(86,3 \%)$ da terceira série - fizeram uso de recursos preventivos na última relação sexual tabela 2.

Tabela 2 - Recursos preventivos utilizados na última relação sexual, segundo sexo (n, \%). Alunos do ı e $3^{\circ}$ ano - UNIFESP / Campus Baixada Santista, 2009

\begin{tabular}{|c|c|c|c|c|c|c|c|c|c|c|c|c|}
\hline \multirow{3}{*}{ USO/ RECURSOS DE PROTEÇÃO } & \multicolumn{6}{|c|}{ PRIMEIRO ANO } & \multicolumn{6}{|c|}{ TERCEIRO ANO } \\
\hline & \multicolumn{2}{|c|}{ M } & \multicolumn{2}{|r|}{$\mathrm{F}$} & \multicolumn{2}{|c|}{ Total } & \multicolumn{2}{|c|}{ M } & \multicolumn{2}{|c|}{$\mathrm{F}$} & \multicolumn{2}{|c|}{ Total } \\
\hline & $n$ & $\%$ & $n$ & $\%$ & $n$ & $\%$ & $n$ & $\%$ & $n$ & $\%$ & $n$ & $\%$ \\
\hline \multicolumn{13}{|l|}{ SIM } \\
\hline Só Cam. masculina & ॥ & 50,0 & 14 & 34,2 & 25 & 39,7 & 2 & 25,0 & 10 & 14,6 & 12 & 16,4 \\
\hline \multicolumn{13}{|l|}{ Camisinha masculina+ } \\
\hline Pílula & 5 & 22,7 & 13 & 31,7 & 18 & 28,5 & - & - & 17 & 25,0 & 17 & 23,3 \\
\hline coito interromp. & - & - & 2 & 4,9 & 2 & 3,2 & - & - & 1 & 1,5 & 1 & 1,4 \\
\hline Tabelinha & - & - & 1 & 2,4 & 1 & 1,6 & 1 & 12,5 & - & - & 1 & 1,4 \\
\hline píl + coito interr. & 1 & 4,5 & 1 & 2,4 & 2 & 3,2 & - & - & 1 & 1,5 & 1 & 1,4 \\
\hline coito + tabel. +pil & - & - & - & - & - & - & - & - & 1 & 1,5 & 1 & 1,4 \\
\hline Só Pílula & 2 & 9,1 & 7 & 17,1 & 9 & 14,2 & 3 & 37,5 & 23 & 33,8 & 26 & 35,6 \\
\hline Pílula+coito interrom. & 1 & 4,5 & 2 & 4,9 & 3 & 4,8 & - & - & 2 & 3,0 & 2 & 2,7 \\
\hline Só Cam. Feminina & 1 & 4,5 & - & - & 1 & 1,6 & - & - & - & - & - & - \\
\hline Só Coito Interrompido & 1 & 4,5 & - & - & 1 & 1,6 & 1 & 12,5 & 1 & 1,5 & 2 & 2,7 \\
\hline Sub-Total & 22 & 100,0 & 40 & 97,6 & 62 & 98,4 & 7 & 87,5 & 56 & 82,4 & 63 & 86,3 \\
\hline \multicolumn{13}{|l|}{ NÃO } \\
\hline Sub-Total & - & - & 1 & 2,4 & 1 & 1,6 & 1 & 12,5 & 12 & 17,6 & 10 & 13,7 \\
\hline Total Geral & 22 & 100,0 & 41 & 100,0 & 63 & 100,0 & 8 & 100,0 & 68 & 100,0 & 73 & 100,0 \\
\hline
\end{tabular}

* Total geral refere-se aos alunos sexualmente ativos, por ocasião da investigação. 
A camisinha masculina, como insumo isolado, foi referida por $39,7 \%$ dos alunos do primeiro ano e por $16,4 \%$ dos alunos do terceiro ano; somada ao uso combinado (com outros procedimentos), o total alcançou $76,2 \%$ e por $45,3 \%$, respectivamente. Esta proporção menor na terceira série se fez em detrimento do uso aumentado da pílula - cujo uso exclusivo alcançou $35,6 \%$ (contra $14,2 \%$ na primeira série) - tabela 2. Acrescenta-se, contudo, a ampliação das proporções do uso exclusivo da pílula, paralelamente ao afrouxamento do uso da proteção em relação à transmissão das doenças sexualmente transmissíveis.

Estes resultados coincidem com o achado de Alves e Lopes (2008) sobre a utilização de recursos preventivos entre jovens universitários, tanto em função do uso de preservativos quanto da pílula. Segundo Bastos e colaboradores (2008), no contexto do namoro, os jovens "negociam" a substituição do condom com seus parceiros mais "fixos", assim, o casal sela uma relação de compromisso baseada no respeito e confiança - desconsiderando, a propósito, os cuidados relativos à prevenção da transmissão das DSTs em geral.

Referenciando a última relação sexual, o motivo da utilização do contraceptivo associou-se, principalmente, à prevenção de gravidez (40,0\% entre alunos do primeiro e $57,1 \%$ entre alunos do terceiro ano). Os alunos conhecem as DSTs, previnem-se contra elas, mas a gravidez parece constituir-se num eixo central de preocupações - particularmente no contexto de relações mais duráveis.

O não uso de proteção na última relação sexual fundamentou-se, igualmente, no argumento: “...foi inesperado", ao lado da alusão à confiança no parceiro em relações estáveis: “...por já conhecer o parceiro há quatro anos, ter uma parceria de segurança [...]". Destacaram-se, por sua vez, outras categorias de discursos tais como: "...não tinha camisinha e estava no intervalo do anticoncepcional oral"; "... não foi necessário por serem duas mulheres". Entre estes fragmentos de discursos destaca-se, ao lado do argumento da imprevisibilidade do intercurso, a confiança no parceiro associada ao relaxamento em torno das medidas de prevenção, assim como a negação das possibilidades de contaminação nas relações entre mulheres, ou seja, nas relações homo e bissexuais. Vale dizer que o uso de camisinha feminina foi referenciado por um aluno, ou seja, numa relação heterossexual.

Enveredando em outras dimensões da prevenção, o estudo voltou-se para os circuitos sociais que circunscrevem trocas de informações sobre práticas preventivas relativas ao comportamento sexual. Ao lado da informalidade das relações/conversas entre amigos (primeiro ano: 57,1\% e terceiro ano: 73,7\%), contingente significativo de alunos, que já haviam iniciado a vida sexual, referiu dialogar com os familiares (54,0\% e 6o,5\%, respectivamente) sobre DSTs. Registra-se, por sua vez, proporção menor de interlocução com profissionais das escolas (30,1\% na primeira e $26,3 \%$ na terceira série) e serviços de saúde $(17,5 \%$ e $27,9 \%$, respectivamente). Evidentemente tais proporções são atravessadas, em maior ou menor grau, pelos diferenciais de comportamento entre homens e mulheres.

Mais alunas (primeiro ano: $73,2 \%$ e terceiro ano: $63,2 \%$ ) buscam serviços de saúde. Esta procura, na grande maioria, teve como propósito obter informações sobre prevenção de gravidez $(86,7 \%$ e $81,4 \%$, respectivamente) - espelhando o peso da responsabilidade da prevenção da gravidez que tradicionalmente recai sobre a mulher. Já, entre os alunos do sexo masculino, os motivos variaram segundo a série - mais alunos do terceiro ano referiram a procura médica tanto para tratamento de alguma doença $(66,7 \%)$ como para obtenção de informações sobre DSTs. Estes dados condizem com os achados de Arcoverde e Wall (2005), os quais afirmam que os homens, culturalmente, não costumam ir aos serviços de saúde; para Araújo e Leitão (2005), eles só procuram quando apresentam sintomas e/ou após iniciativas de automedicação.

A despeito da dispersão das fontes de informação, quase todos os alunos participantes da pesquisa têm conhecimento ou já ouviram falar sobre as DSTs. A AIDS constitui-se na maior preocupação dos alunos, tanto do primeiro $(97,9 \%)$ quanto do terceiro ano (98,5\%), seguida da Sífilis $(65,1 \%$ e 72,3\%, respectivamente) e da Gonorreia (59,6\% e 54,0\%, respectivamente).

Ao lado do medo da ausência de cura, fatores como a inexistência de uma vacina eficaz contra o vírus HIV, a variedade de formas de transmissão, 
seu caráter altamente mutagênico e a degradação imunológica que acarreta, segundo Varella (2006), fazem com que a AIDS se destaque sobre as demais doenças sexuais.

O HPV, citado na quarta posição de importância pelos alunos do primeiro ano $(35,6 \%)$, ascende para o terceiro posto no terceiro ano $(62,8 \%)$. O HPV foi mais referido pelas alunas do que pelos alunos, tanto no primeiro (39,8\%) quanto no terceiro ano $(63,9 \%)$, sinalizando, ao lado da intensificação da atividade sexual, para a consideração de que o HPV se constitui numa doença que acomete mais as mulheres. Segundo Sousa e colaboradores (2008), a falta de informação acerca do próprio vírus, dos sinais e sintomas da infecção, da relação com o câncer cervical e das formas de transmissão podem contribuir para que as mulheres sintam-se mais expostas ao HPV do que os homens.

O nível de conhecimento do HPV variou segundo a série: seu reconhecimento no primeiro ano foi da ordem de 54,1\% e no terceiro de $85,4 \%$ - indicativo da ampliação de preocupação relacionada ao espectro de tempo de vivência de práticas sexuais. Ainda são elevados, entretanto, os valores de desconhecimento referidos à infecção e suas consequências entre os jovens universitários.

Os alunos, em sua maioria, já ouviram falar sobre o HPV, mas têm um conhecimento limitado a respeito de questões específicas relacionadas com a transmissão, com o desenvolvimento de doenças associadas ao HPV e, de forma correspondente, com as formas de prevenção.

Mais da metade dos alunos tanto do primeiro $(65,8 \%)$ quanto do terceiro ano $(76,0 \%)$ que referiram conhecer o HPV alegaram identificar as formas de transmissão citando, particularmente, a transmissão do vírus via relações sexuais - quadro A: “...vírus sexualmente transmitido [...]”. Com um nível residual de referência, raros alunos citaram a transmissão por contato e a materno fetal: "...transmitido por contato íntimo e secreções dos genitais”; “...pode ser transmitido de mãe para filho”. Queiroz e colaboradores (2007) afirmaram que embora a transmissão não sexual ocorra em caráter excepcional, não se pode negar sua ocorrência. O site do Ministério da Saúde registrava, em 2008, informações a respeito - porém, a incorporação destes quesitos parece não ter sido significativa no universo dos alunos.

Os dados referidos pelos alunos revelam, ainda, a presença de informações consideradas incorretas: “...o HPV é transmitido via corrente sanguínea”; "...é transmitido [somente] pelos homens"; "... a transmissão se dá tanto por relações sexuais quanto pelo ar". Segundo Sousa e colaboradores (2008) existem concepções errôneas em relação às formas de transmissão do HPV, entre elas, de que sempre é o homem quem transmite o vírus e que, de forma semelhante ao HIV, o HPV pode ser transmitido por contato sanguíneo.

Mais de 55,0\% dos alunos (do primeiro e terceiro ano) não responderam a pergunta sobre agravos associados à infecção pelo HPV sinalizando para a desinformação prevalente a respeito. Dentre aqueles que responderam a questão, 29,1\% dos alunos do primeiro ano e 39,3\% do terceiro ano afirmaram que o HPV pode levar ao câncer de colo de útero. Se, de alguma forma esta relação é reconhecida pelos alunos, está ausente a consideração de outros cânceres que acometem ambos os sexos. Além disso, não deixa de ser significativa (2,5\% na primeira série e 1,7\% na terceira série) a afirmação errônea de que a AIDS e a Sífilis podem ser causadas pelo vírus do HPV - estas informações são condizentes com as considerações de Arcoverde e Wall (2005).

Proporção considerável de alunos do primeiro $(62,0 \%)$ e do terceiro ano $(66,6 \%)$ respondeu que tanto homens como mulheres podem desenvolver a infecção do HPV. No imaginário deles, entretanto, a doença acomete mais as mulheres do que os homens; ou, ainda, as complicações são mais graves entre elas: "...os sintomas e as implicações aparecem apenas em mulheres"; "...no homem é menos grave, em mulheres pode ter complicações”; “...o vírus não se manifesta em homens, ele só transmite”.

Nesta perspectiva, os homens assumem um papel de veículo propagador do vírus para as mulheres - o que tem suporte científico (Einstein e col., 2009). A absolutização desta postura, entretanto, acaba incidindo na negação do risco de contrair o vírus e desenvolver doenças associadas. Vale dizer, a propósito, que os homens, ainda que em limitada frequência, podem desenvolver câncer de pênis, assim como câncer na cavidade oral (Mendonça e Almeida, 2005; Castro e Bussoloti Filho, 2006). 
Quadro A - Conhecimento referido sobre HPV. Alunos do ıํ e $3^{\circ}$ ano - UNIFESP - Campus Baixada Santista, 2009

\section{\begin{tabular}{l|l} 
Primeiro ano & Terceiro ano
\end{tabular}}

Transmissão

- vírus transmitido em contato direto com órgão sexual,

sexualmente ou não, se manifesta na forma de verrugas.

- vírus que pode ser transmitido através de relações sexuais e

que se não for tratado pode levar a morte.

- o vírus encontra-se inoculado no homem, sem manifestação,

e na relação sem camisinha, a mulher pode pegar o vírus e

desenvolver câncer (se o vírus for do tipo que causa).

- vírus sexualmente transmitido que só causa efeitos e reações

nas mulheres, os homens podem infectar, mas não apresentam a

doença.

- transmitido por relação sexual, afeta principalmente as

mulheres, se não for tratado leva ao câncer no colo do útero.

- transmitida via corrente sanguínea [...]

Consequências

- doença grave que pode levar à esterilidade.

- pode trazer sérios prejuízos ao útero, em alguns casos deve

haver retirada do órgão.

- um vírus que se estabelece no útero da mulher.

- doença que afeta o órgão reprodutivo da mulher.

- é um vírus que em mulheres pode causar câncer no colo do

útero e secreções vaginais. No homem é assintomático.

- aparecem verrugas nos genitais masculino e feminino e podem

se agravar e levar ao câncer.

- leva à herpes genital / espécie de ferida na região genital. câncer.
- transmitido por relações sexuais

- vírus muito disseminado, contágio via sexual.

- transmitida a ambos os sexos no ato sexual.

- é transmitido [somente] pelos homens.

- há vários tipos de papilomavírus, alguns podem causar

- é uma DST que pode ficar no organismo sem manifestar por anos, possui diferentes graus de intensidade, possui diferentes tipos de vírus.

- contato com vírus através da calcinha emprestada e de banheiros públicos.

- [...] transmitido de mãe para filho e pelo ar

- é um vírus que causa câncer no colo do útero.

- um vírus que causa doenças em mulheres, é DST, é comum em mulheres casadas a longo tempo.

- pode causar câncer de colo de útero. 0 vírus não se manifesta em todos os organismos.

- causa câncer e infertilidade.

- é uma DST que forma verrugas na região genitália.

- há diversos tipos de HPV, alguns podem causar, em longo prazo, câncer. Há tipos mais comuns, sua reação no corpo é através de condilomas e pode ser tratado com ácidos ou laser. - gera lesões nos genitais de ambos os sexos: na mulher aparece no colo do útero, pode gerar sintomas incômodos. - formam-se verrugas internas na mulher e externas nos homens.

- se inicia com herpes genital, coceiras e ardência.

- pode ser tão perigoso quanto a AIDS.

\section{Prevenção}

- é uma DST que pode ser prevenida com o uso da camisinha [masculina].

- há vacina para esse tipo de doença [...].

- existe vacina. Percebida mais fácil nos homens, na mulher se aloja na entrada do útero, podendo ser identificado num estágio avançado.

- o exame papanicolau ajuda na prevenção e existe uma vacina, porém ela é cara e não é oferecida pelo sus.

- não tem cura, sua complicação se dá em nível local e não em todo o organismo como o HIV.
- [...] pode ser evitado com uso de preservativo.

- deve-se prevenir com camisinha e com o exame anual com o ginecologista.

- existe vacina que previne[...].

- DST que atualmente possui uma vacina sendo indicada para tomar antes de iniciar a vida sexual.

- existe uma vacina que somente mulheres virgens podem

tomar. Tem a ver com o número de parceiros.

- há indícios [de existência] de pomadas contraceptivas. 
A ideia de que o HPV pode ser prevenido - sendo o preservativo o recurso apontado - foi mais prevalente entre os alunos do terceiro $(82,1 \%)$ do que do primeiro ano $(69,2 \%)$. Se este recurso é indispensável no processo de prevenção, não se pode deixar de considerar que a proteção oferecida pelos preservativos não é integralmente segura (Arcoverde e Wall, 2005). Ao lado das limitações que a camisinha apresenta quanto a proteger da contaminação, fica registrado que a cura da doença não constituiu uma questão aventada pelos alunos, evidenciando ausência de informações básicas sobre os efeitos do HPV. Tais lacunas reforçam a necessidade de esclarecimentos.

Ampliando a consideração da prevenção, a vacina foi mencionada, espontaneamente, por cerca $17,0 \%$ dos alunos de ambos os sexos, como uma das formas de prevenção. Afirmada sua capacidade de proteção, mais de 90,0\% das alunas - tanto do primeiro quanto do terceiro ano - expressaram a disposição para recebê-la. Fica registrada a menção ao questionamento existente sobre a disponibilidade/custo das vacinas, ao lado da capacidade limitada de proteção para os diferentes tipos de vírus.

Proporção significativa de alunos referiu que obtiveram conhecimento sobre o HPV via meios de comunicação (primeiro ano: 30,4\% e terceiro ano: $40,2 \%$ ), seguido da escola/professores (26,6\% e $27,3 \%$, respectivamente). Ao lado das fontes dispersas de informação sinalizadas nestas respostas, destacamos que mais alunos do primeiro $(25,3 \%)$ do que do terceiro ano $(7,7 \%)$ não responderam esta questão, ratificando um maior desconhecimento por parte dos estudantes mais novos ou com menos vivência sexual.

A propósito, mais de 90,0\% dos estudantes afirmaram que gostariam de obter informações sobre DSTs/HPV: “...é sempre bom e importantíssimo obter esse tipo de informação"; "...seria esclarecedor, já que possuo relações sexuais e o HPV parece estar relacionado".

Como forma de conhecerem melhor as doenças, eles sugeriram tanto palestras em escolas/faculdades e programas na mídia como a possibilidade de obtenção destas informações via eletrônica, o que viabilizaria tratar do assunto no plano individual. Neste âmbito, inscrevem-se as referências que se seguem: “...propaganda e palestras em universidades e escolas"; "...educação sexual utilizando meios de comunicação"; "..via e-mail pessoal, por ser mais discreto".

Diante do caráter difuso e informal das fontes de informação sobre o HPV, é expressiva a demanda generalizada por conhecimentos a propósito da transmissão viral e de condutas pertinentes à prevenção em relação ao desenvolvimento da infecção.

\section{Considerações Finais}

A iniciação sexual entre os alunos investigados - em consonância com estudos congêneres - concentrouse na faixa de 15 a 17 anos de idade. Generalizada entre alunos do sexo masculino desde a primeira série dos cursos investigados, a iniciação sexual foi mais tardia entre alunas.

Num contexto de aumento do uso de preservativos, foi constatada elevada proporção de uso do condom no momento da iniciação sexual, evidenciando a valorização de medidas de proteção - no plano do conhecimento - em tempos de liberação sexual. Considerada, porém, a última relação sexual, entre os iniciados, cai a adesão ao uso de preservativos, particularmente entre alunos do terceiro ano, em detrimento do uso do contraceptivo oral. Além disso, não podem ser desconsideradas as resistências manifestas ao seu uso, particularmente por parte dos alunos do sexo masculino.

O não uso de proteção (camisinha masculina) associou-se à imprevisibilidade do intercurso associado às limitações de acesso ao preservativo no momento da ocorrência, à confiança no parceiro(a) e, principalmente, ao uso do contraceptivo oral.

O uso da "pílula”, associado exclusivamente com a contracepção, acaba não só por manter as práticas preventivas aos cuidados da mulher - reafirmando padrões de comportamento precedentes - como pode favorecer a desresponsabilização dos parceiros diante da prevenção da transmissão de DSTs. Nesta linha de considerações, inscreve-se o argumento, indefensável, da isenção de proteção no caso de relações homossexuais femininas. Vale ressaltar, por outro lado, a citação - a ser valorizada - que reconhece o requerimento de controle atestando a ausência de DSTs, compartilhado pelos parceiros, como justificativa para o não uso de proteção. 
Em meio às ambiguidades das práticas de proteção, os alunos referem conhecer as DSTs, valorizando a AIDS, prioritariamente, seguida da Sífilis e, em terceira ou quarta posição de importância, situam o HPV. Os dados indicam que esta infecção ainda é uma novidade, ressaltando que seu reconhecimento é potencializado na medida em que se desenvolve a consciência de risco relacionado à ampliação das vivências sexuais. Tal conhecimento, entretanto, é relativizado no tocante às especificidades da transmissão, das implicações da doença e de sua prevenção - que expõem a vulnerabilidade a que estão sujeitos os jovens, certamente, dentro e fora da universidade.

Apontando basicamente a transmissão viral por via sexual, poucos mencionaram a transmissão não sexual, por contato, e pela via materno fetal. O nível de desconhecimento sobre as consequências acarretadas pelo HPV assume proporções particularmente elevadas. Tais limitações, presentes entre alunos de ambas as séries, acaba por repercutir sobre as formas de consideração da prevenção - que merecem esclarecimentos.

A maioria dos alunos afirmou que tanto homens quanto mulheres podem desenvolver a infecção pelo HPV. No imaginário deles, porém, a doença acomete mais as mulheres do que os homens. Alguns também destacaram que os homens apenas transmitem o vírus, deixando a descoberto, nesta condição, a necessidade de recorrer a medidas de prevenção. Lembrando que as alunas demonstraram ter mais conhecimento tanto sobre as formas de transmissão quanto da prevenção do vírus e das doenças relacionadas à infecção pelo HPV, e que mais alunos do sexo masculino afirmaram que as consequências da doença são mais graves entre as mulheres, ficam explícitos os diferenciais de gênero que permeiam a consideração da questão do HPV a serem contempladas no planejamento de programas de esclarecimentos.

Pequena proporção de alunos mencionou a vacina como recurso preventivo, particularmente no segmento masculino. Ao lado da dúvida existente sobre sua disponibilidade/custo, quase todas as alunas afirmaram a disposição para recebê-la.

Alertados para a relevância do HPV/DST e cientes das limitações de seus conhecimentos, os estudan- tes, tanto do primeiro quanto do terceiro ano, ou seja, independentemente da idade, expressaram a demanda por esclarecimentos. É imperioso trabalhar informações relativas à transmissão da infecção pelo HPV, ao lado da consideração das práticas contraceptivas, reafirmando a possibilidade de tratamento e cura na interceptação do desenvolvimento da infecção.

\section{Referências}

ALVES, A. S.; LOPES, M. H. B. M. Uso de métodos anticoncepcionais entre adolescentes universitários. Revista Brasileira de Enfermagem, Brasília, DF, v. 61, n. 2, p. 170-177, 2008.

ARAÚJO, M. A. L.; LEITÃO, G. C. M. Acesso à consulta a portadores de doenças sexualmente transmissíveis: experiências de homens em uma unidade de saúde de Fortaleza, Ceará, Brasil. Cadernos de Saúde Pública, Rio de Janeiro, v. 21, n. 2, p. 396-403, 2005.

ARCOVERDE, M. A. M.; WALL, M. L. Assistência "prestada ao ser" masculino portado do HPV: contribuições de enfermagem. DST Jornal Brasileiro de Doenças Sexualmente Transmissiveis, Rio de Janeiro, v. 17, n. 2, p. 133137, 2005 .

AYRES, J. R. C. M. et al. Vulnerabilidade e prevenção em tempos de Aids. In: BARBOSA, R.; PARKER, R. (Org.). Sexualidade pelo avesso: direitos, identidades e poder. Rio de Janeiro: Relume Dumará, 1999. p. 50-71.

BASTOS, M. R. et al. Práticas contraceptivas entre jovens universitárias: o uso da anticoncepção de emergência. Texto Contexto Enfermagem, Florianópolis, v. 17, n. 3, p. 447-456, 2008.

BORGES, A. L. V.; SCHOR, N. Início da vida sexual na adolescência e relações de gênero: um estudo transversal em São Paulo, Brasil, 2002. Cadernos de Saúde Pública, Rio de Janeiro, v. 21, n. 2, p. 499507,2005 .

BRICKS, L. F. Vacina HPV: nova perspectiva na prevenção de câncer. Pediatria, São Paulo, v. 29, n. 2, p. 154-156, 2007. 
CARVALHO, A. L. S. et al. Sentimentos vivenciados por mulheres submetidas a tratamento para papillomavirus humano. Escola Anna Nery Revista Enfermagem, Rio de Janeiro, v. 11, n. 2, p. 248-253, 2007.

CASTELLSAGUÉ, X. Natural history and epidemiology of HPV infection and cervical cancer. Gynecologic Oncology, Barcelona, v. 110, n. 3, p. S4-7, 2008. Supplement 2.

CASTRO, T. P. P. G.; BUSSOLOTI FILHO, I. Prevalence of human papillomavirus (HPV) in oral cavity and oropharynx. Brazilian Journal of Otorhinolaryngology, São Paulo, v. 72, n. 2, p. 272 282, 2006.

COSTA, F. H. M. Estudo da prevalência de papilomavírus humano (HPV) em urinas de homens infectados pelo HIV-1 na cidade de São Paulo, Brasil. 2008. Tese (Mestrado em Ciências) Universidade de São Paulo, São Paulo, 2008.

EINSTEIN, M. H. et al. Clinician's guide to human papillomavirus immunology: knowns and unknowns. Lancet Infectious Disease, Kidlington, v. 9, n. 6, p. 347-356, 2009.

FRIGATO, S.; HOGA, A.K. Assistência à mulher com câncer de colo uterino: o papel da enfermagem. Revista Brasileira de Cancerologia, Rio de Janeiro, v. 49, n. 4, p. 209-214, 2003.

GUERRA, V. M.; GOUVEIA, V. V. Liberalismo / Conservadorismo sexual: proposta de uma medida de multi-fatorial. Psicologia: Reflexão e Crítica, Porto Alegre, v. 20, n. 1, p. 43-53, 2007.

HEILBORN, M. L. et al. Gênero e carreiras sexuais e reprodutivas de jovens brasileiros. In: XV-ENCONTRO NACIONAL DE ESTUDOS POPULACIONAIS, ABEP, Caxambu, p. 1-24, 2006.
MENDONÇA, M. L.; ALMEIDA NETTO, J. C. Importância da infecção pelo papilomavírus humano em pacientes do sexo masculino. DST - Jornal Brasileiro de Doenças Sexualmente Transmissíveis, Rio de Janeiro, v. 17, n. 4, p. 306310, 2005 .

NAGAKAWA, J. T. T.; SCHIRMER, J.; BARBIERI, M. Vírus HPV e câncer de colo de útero. Revista Brasileira de Enfermagem, São Paulo, v. 63, n. 2, p. 307-311, 2010.

PAIVA, V. et al. Idade e uso de preservativo na iniciação sexual de adolescentes brasileiros. Revista de Saúde Pública, São Paulo, v. 42, n. 1, p. 45-53, 2008.

QUEIROZ, A. M. A.; CANO, M. A. T.; ZAIA, J. E. O papiloma vírus humano (HPV) em mulheres atendidas pelo SUS, na cidade de Patos de Minas - MG. Revista Brasileira Análise Clínica, Rio de Janeiro, v. 39, n. 2, p. 151-157, 2007.

SANKARANARAYANAN, R. HPV vaccination: the promise \& problems. Indian Journal Medical Research, New Delhi, v. 130, n. 3, p. 322-326, 2009. SOUSA, L. B.; PINHEIRO, A. K. B.; BARROSO, M. G. T. Ser mulher portadora do HPV: uma abordagem cultural. Revista Escola Enfermagem, São Paulo, v. 42, n. 4, p. 737-743, 2008.

VARELLA, R. B. Aspectos da epidemia de AIDS em município de médio porte do Rio de Janeiro, 200o2004. Revista Brasileira de Epidemiologia, São Paulo, v. 9, n. 4, p. 447-453, 2006.

VIEIRA, M. A. S. et al. Fatores associados ao uso do preservativo em adolescentes do gênero feminino no município de Goiânia. DST - Jornal Brasileiro de Doenças Sexualmente Transmissíveis, Rio de Janeiro, v. 16, n. 3, p. 77-83, 2004. 